\title{
Jean-Jacques Rousseau: Sociedade e Educação
}

Antoniel dos Santos Gomes Filho ${ }^{1}$; Lielton Maia Silva ${ }^{2}$; Sandra Mary Duarte ${ }^{3}$

Resumo: A partir de uma revisão das obras: O Contrato Social (2014) e O Emílio, ou; Da Educação, do filósofo francês Jean-Jacques Rousseau; bem como de textos de pesquisadores comentadores do referido teórico, objetivamos nesse estudo apresentar e discutir o pensamento de Jean-Jacques Rousseau em relação a (01) Sociedade e (02) Educação, buscando compreender as continuidades e rupturas das ideias apresentadas na contemporaneidade. A obra de Rousseau no curso sócio-histórico teve, e ainda tem grande influência sobre as formas de observar e refletir a sociedade e a educação em âmbito inter-nacionais. De sua obra são suscitadas reflexões sobre a criança, o cidadão, a organização e relação social, entre outros temas que dialogam com a contemporaneidade, mesmo, sendo seus escritos datados do século XVIII. A atemporalidade das ideias de JeanJacques Rousseau, são fundamentais para pesquisadores/as da educação e de outros campos do saber, sendo assim pertinente a discussão proposta neste estudo, proporcionando um diálogo inter e transdisciplinar sobre os temas apresentados.

Palavras-Chave: Jean-Jacques Rousseau. Educação. Sociedade.

\section{Jean-Jacques Rousseau: Sociedad Y Educación}

Resumen: A partir de una revisión de las obras: El contrato social (2014) y Emile, o; La educación, el filósofo francés Jean-Jacques Rousseau; así como textos de investigadores del teórico anterior, este estudio tuvo como objetivo presentar y discutir el pensamiento de Jean-Jacques Rousseau en relación con (01) y Sociedad (02) Educación, buscando entender las continuidades y rupturas del que se presentan en las ideas contemporáneas. La obra de Rousseau en el curso histórico-social tenido, y todavía tiene gran influencia en la manera de observar y reflejar la sociedad y la educación en el nivel inter-nacional. De su trabajo se plantean reflexiones sobre el niño, el ciudadano, la organización y las relaciones sociales, entre otros temas que el diálogo con la contemporánea, incluso con sus escritos fechados del siglo XVIII. La intemporalidad de las ideas de Jean-Jacques Rousseau son esenciales para los investigadores / la educación y otros campos del conocimiento, y por lo tanto relevante a la discusión propuesto en este estudio, proporcionando un diálogo inter y transdisciplinaria sobre los temas presentados.

Palabras-Clave: Jean-Jacques Rousseau. Educación. Sociedad.

\footnotetext{
${ }^{1}$ Mestrando em Educação Brasileira na Universidade Federal do Ceará (UFC), vinculado à Linha de História da Educação Comparada (LHEC). Discente de Licenciatura em Filosofia na Faculdade Católica de Fortaleza (FCF). Tecnólogo em Gestão Comercial pelo Centro Universitário Dr. Leão Sampaio (UNILEÃO). E-mail: antoniel.historiacomparada @ gmail.com

${ }^{2}$ Docente do curso de Psicologia da Faculdade Vale do Salgado (FVS). Especialista em Saúde Mental pela Universidade Católica . . . B Bosco. Bacharel em Psicologia pelo Centro Universitário Católica de Quixadá (UNICATÓLICA). E-mail: lieltonmaia@ fvs.edu.br

${ }^{3}$ Docente do curso de Psicologia da Faculdade Vale do Salgado (FVS). Mestre em Ciências da Educação pela Universidade de Trás-os-Montes e Alto Douro, UTAD, Portugal. Bacharel em Psicologia pelo Centro Universitário Católica de Quixadá (UNICATÓLICA). Licenciada em Pedagogia pela Universidade Estadual do Ceará (UECE). E-mail: sandramary@ fvs.edu.br
} 


\section{Considerações Iniciais}

A educação constitui-se de uma construção social um fenômeno humano, logo, permeia as relações humanas desde seus primórdios, estando organizadas tanto pelo ensino e aprendizagem através da oralidade entre gerações, até quando foi sistematizada em níveis graduais e hierárquicos, assim como conhecemos hoje.

Entender historicamente a organização da educação em âmbito mundial, tendo como marco o advento da modernidade é fundamental para estabelecer conexões em aspectos nacionais, regionais e locais, visto que, a educação brasileira foi, e é influenciada por essa seara de ideias sobre o educar.

Sócio-historicamente diversos são os/as teóricos/as que contribuíram para o desenvolver um pensamento sobre a educação, são nomes que poderiam ser suscitados numa imensa lista inter-nacional: Jean-Jacques Rousseau, Anton Makarenko, Émile Durkheim, John Dewey, Maria Montessori, Anísio Teixeira, Paulo Freire, entre outros, que através de diferentes modos observaram e contribuíram para o fenômeno humano educação. Entre eles, o já mencionado filósofo francês Jean-Jacques Rousseau e sua obra trata de assuntos como sociedade e educação, que foram nossos alvos de investigação neste estudo, como diz Soëtard (2010) a obra de Rousseau teve uma grande influência para o desenvolvimento do movimento pedagógico, o que justifica o estudo de tais obras, mesmo estas sendo criadas no século XVIII.

Diante de tantos olhares e formulações teóricas sobre a educação, pesquisadores da educação apresentam matrizes teóricas, que agregam ideias comuns ou similares de teóricos/as a fim de facilitar didaticamente as compreensões sociais e históricas sobre um determinado modo de pensar a educação, o que não anula as conexões com o atual panorama educacional inter-nacional. Nesse sentido o presente estudo tem como objetivo apresentar e discutir o pensamento de Jean-Jacques Rousseau em relação à (01) Sociedade e (02) Educação, buscando compreender as continuidades e rupturas das ideias apresentadas na contemporaneidade. Metodologicamente, optamos por uma abordagem qualitativa (FLICK, 2009) tendo como suporte uma revisão de literatura (HOHENDORFF, 2014) sendo as obras: O contrato social (2014) e Emílio; ou, Da educação (1995) de Jean-Jacques Rousseau base para a discussão proposta no texto. 
Além dessas obras, também foram utilizados textos sobre história da educação (ARANHA, 2006; CAMBI, 1999; LARROYO, 1970), além de textos de teóricos comentadores da obra de Jean-Jacques Rousseau (STRECK, 2008; MICHEL SOËTARD, 2010), que nos ajudaram a compreender e discutir como o autor estudado formulou suas ideias sobre a sociedade e a educação em seu tempo e realidade social.

O estudo segue estruturado da seguinte forma: além dessas considerações iniciais, o estudo apresenta uma seção intitulada: Jean-Jacques Rousseau: sociedade e educação, onde apresentamos e desenvolvemos as discussões das obras do autor em conjunto com os textos de educação e dos comentadores de Rousseau, após essa seção, tem-se as considerações finais do estudo, onde realizamos um resumo do exposto, bem como situamos o Rousseau e suas ideias na contemporaneidade.

\section{Jean-Jacques Rousseau: Sociedade e Educação}

Durante os séculos XVII e XVIII a sociedade européia passou por uma série de mudanças sociais, culturais e científicas. O modo de pensar começará a mudar, assim como, as estruturas sociais que organizavam a sociedade numa economia feudal, baseada num poder monárquico inerente do período medieval. As teorias/ideias anunciadas durante esses séculos rompiam com os paradigmas de pensamento instaurados pela igreja teocentrista e pela aristocracia absolutista do antigo regime. Assim, o iluminismo como ficou conhecido esse movimento/momento, valorizou as ciências e a educação, e colocou o homem ${ }^{1}$ no centro do pensamento e da razão, num movimento antropocêntrico (VASCONCELOS, 2010).

O Iluminismo ao introduzir o pensamento antropocêntrico, colocou em pauta o racionalismo do homem enquanto sujeito que tem o poder de discernimento, distinção e comparação, rompendo com a tradição do dogmatismo comum nas sociedades medievais, colocando nas "mãos" do homem o poder das escolhas (coletivas) econômicas, políticas,

\footnotetext{
1 Nota explicativa: Entende-se pela expressão homem nesse momento texto, não as questões que envolvem o sexo numa dualidade (masculino-feminino / homem-mulher), mas sim, as questões de unidade ontológica que congregam a reflexão que abrange o ser humano. Vale ressaltar que quando se discute sobre a educação da mulher no final do texto, as expressões homem e mulher são utilizadas no sentido de atribuição sexo-anatômica. 
judiciárias, sendo este o momento em que o homem começa a ter força de escolha no campo da individualidade (ARANHA; MARTINS, 2009; VASCONCELOS, 2010).

O pensamento iluminista foi marcado por diversas correntes, como nos lembra Himmelfarb (2011, p. 18) ao discordar de Peter Gay que defende apenas um Iluminismo com base em um "único estilo de pensamento". Nas palavras de Himmelfarb:

[...] o Iluminismo britânico representa "a sociologia da virtude"; o francês "a ideologia da razão"; o americano, "a política da liberdade". Os filósofos britânicos eram mais sociólogos do que filósofos; preocupados com o homem em relação à sociedade, eles viam as virtudes sociais como base para uma sociedade saudável e humana. Os franceses tinham uma missão mais excelsa: fazer da razão o princípio condutor tanto da sociedade quanto das mentes; "racionalizar", por assim dizer, o mundo. Os americanos, mais modestamente, visavam criar uma "nova ciência da política", que estabeleceria a nova república sobre a sólida fundação da liberdade (HIMMELFARB, 2011, p. 34-35).

Essa abrangência do pensamento nos coloca diante de diversos nomes importantes e de representatividade desse período: Adam Smith, John Locke, Isaac Newton, Jean-Jacques Rousseau, Voltaire, Francis Bacon, Jean le Rond d'Alembert, Denis Diderot e Montesquieu são alguns nomes que atravessam o período iluminista. As ideias iluministas além de questionarem os aspectos econômicos, políticos e judiciários, também debateram sobre a educação, e como está deveria ser para formar os homens para uma sociedade livre e liberal.

Jean-Jacques Rousseau foi um dos teóricos do século XVIII que contribuíram para pensar essa nova sociedade, como também na educação do homem para essa nova sociedade. Sua obra abrange uma reflexão sobre as relações diante dos contratos sociais estabelecidos pelos homens uma sociedade democrática. Nesse sentido, compreender a educação em Rousseau requer uma visualização mesmo que sucinta de seus escritos e ideias sobre sociedade e política, como também do curso de sua vida pessoal e intelectual nos círculos acadêmicos de Paris dos anos 1700.

Nascido em Genebra, Suíça no ano de 1712, em uma família de origem francesa, sua mãe morreu após seu nascimento de complicações no parto e foi abandonado pelo pai aos dez anos, ficando sobre os cuidados de um tio e sendo criado na tradição protestante. Aos dezesseis anos abandonou Genebra para viver viajando entre a Itália, a França e a Suíça. Entre os anos de 1735 e 1739 foi acolhido por Madame Louise de Warens, senhora rica que influenciou sua formação cultural, quando em sua residência, a chamada Les Charmettes, estudou história, literatura, filosofia e música. Em 1740 foi preceptor em Lyon, e em 1742 fixa residência em 
Paris, considerada a capital intelectual da Europa, exercendo as atividades de professor, copista e secretário de um embaixador, realizando visitas em Veneza no ano de 1743 em função de suas atividades como secretário. Em sua volta a Paris liga-se aos philosophes, um grupo de intelectuais franceses do período iluminista que buscavam subverter o Antigo Regime e fazer uma Revolução Social, a Encyclopédie constituía seu principal veículo de comunicação, tanto que foram editados 28 volumes, lançados entre 1751 e 1772. Rousseau ligado ao filósofo Denis Diderot colabora com a Encyclopédie escrevendo sobre música e política, tendo seu artigo político intitulado: Discurso sobre as ciências e as artes, premiado em 1750 na Academia de Dijon. No romance A nova Heloísa, iniciado em 1756 e publicado em 1760, obteve um enorme sucesso, pois fazia um retorno aos modos de vida natural. Em 1762 foi publicado $O$ Emílio ou Da Educação, uma obra pedagógica, e, O Contrato Social, sua obra sobre política. As obras foram condenadas em Paris e Genebra por seu conteúdo, que seria responsável pelos ideários da Revolução Francesa em 1789, o que obrigou sua saída de Paris, passando pela Prússia e Inglaterra. Durante o período de perseguição sofreu alterações no seu equilíbrio psíquico, adquirindo manias de perseguição e atormentado por uma ideia de complô contra sua pessoa, o que levou a escrever as Confissões de 1765 a 1770, e Os devaneios do caminhante, iniciado em 1776 até sua morte em 1778 na França, em 2 de julho de 1778 em Ermenonville. Rousseau foi casado com Théresè Levasseur e tiveram cinco filhos que foram entregues à adoção, os sentimentos advindos desse ato marcaram grande parte de sua obra, inclusive seu tratado de educação, o Emílio (CAMBI, 1999; ROUSSEAU, 2014; ARANHA, 2006; HIMMELFARB, 2009; NOVA ESCOLA, 2009; ARANHA; MARTINS, 2009).

Analisar a educação em Rousseau considerado por muitos pesquisadores o "pai" da pedagogia moderna, requer uma leitura cruzada entre O Contrato Social e O Emílio, pois as obras são complementares. Se no Contrato Social, Rousseau apresenta um novo modo de organização social, cujo poder está nas mãos dos homens livres para realizar seus contratos políticos e disputar o poder de modo democrático, no Emílio é apresentado um novo modo de ensino, um novo modelo para desenvolver os homens para essa sociedade que está nascendo. Afinal, não seria possível uma nova sociedade sem novos homens, que compreendessem e legitimassem esses novos contratos sociais.

Como defendido por Rousseau (1995) no livro quinto do Emílio, os homens devem conhecer a sociedade no qual serão homens e cidadãos, e realizaram seus contratos com outros 
homens, desse modo, sua educação deve apresenta-lo aos regimes de governo existentes, para compreender como funciona a engrenagem social, estando esse homem e cidadão apto para compreender a vida em sociedade sem ser manipulado por outrem, mas sim interpretando o mundo com seus sentidos que foram estimulados durante sua infância.

Junto com John Locke e Thomas Hobbes, Rousseau fez parte da corrente de pensamento contratualista que buscou um fundamento racional para discutir o poder soberano, afastando-se da teoria do direito divino dos reis, colocando a natureza humana como fonte dos direitos e do poder. Logo, o poder não se justifica no divino, mas sim na representatividade e consenso da maioria da população num processo democrático direto, como ressalta Aranha e Martins (2009).

"O homem nasceu livre e em toda parte é posto a ferros." (ROUSSEAU, 2014, p. 23 24). Noutras palavras já conhecidas: o homem nasce bom e a sociedade o corrompe, mas, a "[...] ordem social é um direito sagrado que serve de base a todos [os homens]. No entanto, esse direito não vem da natureza, ele está fundando sobre convenções [sociais].”. Nesse sentido observamos que as interações no âmbito social são construídas por homens e para os homens, desse modo, para que o pacto social seja legítimo os homens devem passar de um estado de natureza, para o estado civil, unindo e dirigindo suas forças num movimento de agregação para fazer sua vontade agir de comum acordo, ou seja, uma vontade geral representada pelo soberano que não atua em vontade própria, mas na vontade geral.

As instituições inseridas na sociedade de acordo com Rousseau têm a função de desnaturalizar o homem e retira-lo de seu estado de natureza, ou seja, o estado no qual nasceu, formando-o como cidadão que comunga agora de uma unidade social que é membro, e não mais de um eu unitário e total. Nas palavras de Rousseau:

\footnotetext{
O homem natural é tudo para ele; é a unidade numérica, é o absoluto total, que não tem relação senão consigo mesmo ou com seu semelhante. $\mathrm{O}$ homem civil não passa de uma unidade fracionária presa ao denominador e cujo valor está em relação com o todo, que é o corpo social. As boas instituições sociais são as que mais sabem desnaturar o homem, tirar-lhe sua existência absoluta para dar-lhe outra relativa e colocar o $e u$ na unidade comum, de modo que cada particular não acredite mais ser um, que sinta uma parte da unidade, e não seja mais sensível senão no todo (ROUSSEAU, 1995, p.13).
}

A educação é algo contínuo que segue o homem por toda sua vida, não estando apenas ligadas às instituições educacionais, nesse sentido, a educação do Emílio não ocorre apenas em um local, num determinado período de tempo, amparado por uma série de conteúdos 
programados, mas no "[...] livre desenvolvimento da própria natureza da criança, de suas inclinações naturais.” (PILETTI; PILETTI, 1991, p. 121). Nesse sentido Rousseau faz uma crítica à educação livresca: "O abuso dos livros mata a ciência. Acreditando saber o que temos, acreditamos dispensados de aprender. Leituras excessivas não servem senão para fazer ignorantes e presunçosos." (ROUSSEAU, 1995, p. 543). Esses posicionamentos advêm de um olhar educacional que privilegia a experiência da criança em seu processo de formação, sendo apenas no período de 12 a 15 anos que o Emílio de fato tem seus primeiros contatos com os livros, pois seus sentidos e sentimentos já foram desenvolvidos, logo, o Emílio pode formular uma opinião sobre os fatos que lhes são apresentados ou experiênciado.

A pedagogia inaugurada por Rousseau como já percebida coloca a criança no centro do processo de ensino, ele foi o "pedagogo que inventou a infância" (STRECK, 2008, p. 9). Antes dessa "invenção" a criança era considerada um adulto em miniatura, sendo tratada como um adulto no que se referem às roupas, os comportamentos, os modos de ensino, etc. Soëtard (2010, p. 12) aponta que Rousseau participou em seu tempo do desenvolvimento de um "sentimento pela infância", uma vez que, "moralistas, autoridades administrativas e médicos redobravam os argumentos para incitar as mães a se ocuparem com sua prole, começando pelo aleitamento.”.

Rousseau só faz anúncio de suas regras pedagógicas depois de muito observar a vida infantil, assim o educador ou preceptor deve conhecer aquele quem educa, como é demonstrado na relação entre Emílio e seu preceptor. Esse conhecimento proporciona ao preceptor desenvolver seu trabalho a partir das condições de aprendizado da criança, ou seja, entender as demandas das crianças é fundamental na pedagogia proposto por Rousseau (LARROYO, 1970).

Desse modo, "Rousseau critica de início toda a forma de educação fundada sobre o princípio de uma autoridade que submeta a vontade da criança à de seu mestre." (SOËTARD, 2010, p. 16), para Rousseau depois que a criança, ou o homem conquistar sua própria autonomia e liberdade diante da realidade do mundo e dos outros homens é que o preceptor/professor entra em cena, favorecendo a,

[...] experiência formadora, acompanhando a criança ao longo de todo o seu itinerário, pleno de provas e de emboscadas, enfim e sobretudo, estimulando-o no momento em que se deve esforçar-se por reconstituir-se, por meio da ruptura de seu desejo. A arte do pedagogo consiste em atuar de maneira tal que sua vontade não substitua jamais a vontade da criança (SOËTARD, 2010, p. 17). 
O fato de colocar a criança no centro da educação, juntamente com uma defesa ferrenha do educador/preceptor em conhecer a criança e suas demandas, influenciou uma série de teorias posteriores, em especial no campo da psicologia da educação (STRECK, 2008; LARROYO, 1970; PILETTI; PILETTI, 1991).

A mulher e sua educação também obtiveram espaços na obra e no pensamento de Rousseau, mesmo que este tenha dedicado apenas o livro V do Emílio para falar sobre a educação de Sofia. "A mulher aparece na educação de Emílio quando este precisa ser introduzido na sociedade. Ela é, por assim dizer, a porta de entrada para o mundo perigoso do qual Emílio havia sido cuidadosamente protegido.” (STRECK, 2008, p. 47).

Vale destacar que logo no início do Livro V, de o Emílio Rousseau se utiliza de uma visão que ao mesmo tempo indica uma suposta "igualdade" entre homens e mulheres, mesmo que este destaque diferenças de ordem biológica, ao mesmo tempo se utiliza de uma ideia de natureza/natural para definir o papel social do homem e da mulher na sociedade. Tal questão pode parecer "confusa", o que de fato foi no tempo de Rousseau as questões que envolviam o sexo (anatômico e fisiológico) como nos lembra Streck (2008), desse modo achamos necessário reproduzir na íntegra os primeiros trechos do livro V - Sofia ou a Mulher.

Sofia deve ser mulher como Emílio é homem, isto é, ter tudo o que convém à constituição de sua espécie e de seu sexo para ocupar seu lugar na ordem física e moral. Comecemos portanto a examinar as conformidades de seu sexo com o nosso e as diferenças entre ambos.

Em tudo o que não se prende ao sexo, a mulher é homem: têm os mesmos órgãos, as mesmas necessidades, as mesmas faculdades; a máquina é construída da mesma maneira, as peças são as mesmas, o jogo de ambos é igual, o aspecto semelhante; e sob qualquer ângulo que os considerarmos só diferem por mais ou por menos.

Em tudo que diz respeito ao sexo, a mulher e o homem têm em tudo relações e em tudo diferenças: a dificuldade de compará-los vem de determinar, na constituição deles, o que é do sexo e o que não é. Pela anatomia comparada, e mesmo pela simples inspeção, encontramos entre ambos diferenças gerais que parecem não provir só sexo; cabem ao sexo porém, mas através de ligações que não podemos perceber: não sabemos até onde tais ligações podem estender-se; a única coisa que sabemos com certeza é que tudo o que tem em comum é da espécie, e o que tem de diferente e do sexo. Deste duplo ponto de vista, encontramos entre ambos tantas relações e tantas oposições, que talvez seja uma das maravilhas da natureza ter feito dois seres tão semelhantes constituindo-se tão diferentes.

Tais relações e tais diferenças devem influir no moral; esta consequência é sensível, conforme à experiências, e mostra a futilidade das discussões acerca da preferência ou da igualdade dos sexos: como cada um deles, atendendo aos fins da natureza segundo sua distinção particular, não fosse mais perfeito nisso do que se assemelhando mais ao outro! No que tem de comum são iguais, no que tem de 
diferentes, não são comparáveis. Uma mulher perfeita e um homem perfeito não devem assemelhar-se nem de espírito nem de fisionomia, e a perfeição não é suscetível nem de mais nem de menos.

$\mathrm{Na}$ união dos sexos cada qual concorre igualmente para o objetivo comum, mas não da mesma maneira. Dessa diversidade nasce à primeira diferença assimilável entre as relações morais de um e de outro. Um deve ser ativo e forte, o outro passivo e fraco: é necessário que um queira e possa, basta que o outro resista pouco,

Estabelecido este princípio, segue-se que a mulher é feita especialmente para agradar ao homem. Se o homem deve agradar-lhe por sua vez, é necessidade menos direta: seu mérito está na sua força: agrada, já, pela simples razão de ser forte. Não se trata da lei do amor, concordo; mas é da natureza, anterior ao próprio amor.

Se a mulher é feita para agradar e ser subjugada, ela deve tornar-se agradável ao homem ao invés de provocá-lo. Sua violência está nos seus encantos, é por eles que ela deve constrangê-los a encontrar sua força e empregá-la. A arte mais segura de animar essa força consiste em fazê-la necessária pela resistência. Então o amorpróprio une-se ao desejo, e um triunfa da vitória que o outro o obrigou a ganhar. Daí nascem o ataque e a defesa, a ousadia de um sexo e a timidez do outro, finalmente a modéstia e o pudor com que a natureza armou o fraco para escravizar o forte (ROUSSEAU, 1995, p. 423-424-425).

Como pode-se perceber uma das dificuldades de Rousseau é dizer o que é do sexo masculino e o que é do sexo feminino, ao longo do texto inicial pode-se ver que o próprio autor concorda que as mulheres e os homens são portadores de uma igualdade na constituição dessa máquina que é o corpo humano, sendo apenas diferentes em relação ao sexo, ou seja, as genitálias, que podem ser vistas por uma "simples inspeção".

Outro ponto de a ser discutido é que Rousseau não nega as faculdades intelectuais da mulher, como pode ser visto no seguinte trecho: "Em tudo o que não se prende ao sexo, a mulher é homem: têm os mesmos órgãos, as mesmas necessidades, as mesmas faculdades [...]" (IBIDEM), essa não negação abre precedentes para sua educação, mesmo que esta educação seja para ser socialmente subordinada ao homem. Para explicar as posições ocupadas pelos homens e pelas mulheres na sociedade Rousseau toma como meio de explicação o sexo e relação sexual, ou seja, ele toma como princípio a atividade e a passividade sexual para localizar o homem e a mulher e as características que seriam inerentes a cada um deles, assim o homem ativo é forte e a mulher passiva é fraca.

Frente a essa ideia natural Rousseau aponta que a mulher possui uma certa posição de submissão em relação ao homem: "Se a mulher é feita para agradar e ser subjugada, ela deve tornar-se agradável ao homem" (IBIDEM), mas é interessante perceber que Rousseau reconhece que a mulher também pode exercer poder sobre o homem, não no sentido social, mas através dos mistérios e da timidez feminina, sendo a mulher capaz de "escravizar o forte". 
Se para Streck (2008, p. 49) Rousseau “[...] toma uma decididamente o lado conservador." no que tange às relações de gênero em sua época, nós pensamos que o posicionamento Rousseau não pode ser enquadrado sob um olhar puramente conservador, uma vez que, como é perceptível o próprio aparentemente apresenta uma confusão (mesmo que inicial) para pensar sobre o homem e a mulher, dando a mulher o espaço social da educação (mesmo está sendo vigiada para que os limites da natureza da mulher não fossem exercidos), espaço este que era maciçamente destinado aos homens. Rousseau busca no que na contemporaneidade entendemos por construções históricas e sociais dos papéis de gênero, uma forma para delinear o que é próprio do aprendizado da mulher.

Como aponta Streck (2008) Sofia será educada em um convento, e de acordo com sua natureza "tímida", e, já que as meninas gostam de brincar de bonecas, sua aprendizagem será voltada às atividades práticas, tal como a costura, uma vez que Sofia será mãe, "[...] a mãe cidadã que criará o cidadão para a sociedade do contrato." (ID, p, 51), que diante de um casamento onde a felicidade da mulher dar-se-á pela felicidade do homem, sendo o casamento mais um dos contratos sociais. Portanto, a educação da mulher pensada por Rousseau também vai de encontro a essa nova sociedade postulada no Contrato Social (2014), sendo necessário educar ambos os sexos para conviver nessa nova sociedade.

\section{Considerações Finais}

No início do texto apresentamos a cena e os atores sociais no qual filósofo francês JeanJacques Rousseau estava inserido, assim o mesmo foi um dos contribuintes para as ideias iluministas, junto com outros filósofos de seu tempo. Posteriormente apresentamos uma breve biografia de Rousseau, uma vez que, acreditamos da necessidade de conhecer os caminhos de vida do teórico em estudo, para perceber como suas experiências influenciam em sua obra. Nesse sentido destacamos o fato de Rousseau ter tido pai de cinco filho que foram entregues à adoção, e os sentimentos advindos desse ato marcaram grande parte de sua obra, inclusive seu tratado de educação, o Emílio.

Apresentamos as ideias contidas na obra O Contrato Social, onde Rousseau vai pensar uma nova sociedade, onde a vontade geral seria respeitada, e onde os contratos sociais 
embasado numa democracia seria firmado entre os homens desta sociedade, sendo assim, é necessário que se eduque os novos homens para essa sociedade, por isso, como salientamos a obra O Contrato Social está imbricado na obra O Emílio, ou; Da Educação, um tratado sobre educação, onde Rousseau expõe suas ideias sobre como educar o homem para a sociedade. A mulher também é alvo das ideias sobre educação na obra de Rousseau, como salientamos no último momento do texto, o filósofo dedica-se a pensar sobre como deve ser a educação da mulher para a sociedade do contrato, e ressalta que esta educação está correlacionada a uma natureza do sexo, por isso a diferença na educação de homens e mulheres.

A partir das questões apresentadas no decorrer do texto pode-se dizer que Rousseau contribui fortemente para um novo olhar sobre a educação e a pedagogia, uma vez que, "inventa" a infância e coloca a criança no centro da aprendizagem, como agente ativo dos processos de ensino. Como diz Streck (2008, p. 88), "Rousseau nos desafia a ver a criança na criança e o homem no homem [...]" desse modo, muda-se a visão da criança como mini adulto. A ideia de Rousseau sobre a educação por fases, influenciou de modo direto ou indireto outros teóricos da educação que buscaram compreender o processo de ensino-aprendizagem, tendo sua expressão maior na obra de Jean Piaget.

As ideias sobre sociedade presente em O Contrato Social, tiveram grande influência na América Latina e no Brasil. No caso histórico do Brasil as ideias de Rousseau e do iluminismo foram fortemente combatidas, como diz Streck:

\begin{abstract}
Na história do Brasil, dois fatos da época em que Rousseau escrevia seus livros são importantes. Um deles é a expulsão dos jesuítas em 1759 pelo Marquês de Pombal, e outro é a Inconfidência Mineira, sob liderança de Tiradentes (morto em 21 de abril de 1792). O primeiro tem a ver com a passagem da responsabilidade da educação para as mãos do Estado, como um dever e um direito público, e o segundo, com a busca de alternativas políticas que favorecessem a liberdade. Em ambos se sentem pulsar as ideias revolucionárias de Rousseau, que, por essa época, muitos estudantes da elite brasileira absorviam nas universidades de Portugal e da França (ID, p. 82).
\end{abstract}

Ainda aponta o autor, os livros de Rousseau, em especial O Contrato Social foram alvos do Tribunal do Santo Ofício na Inquisição, o que é um demonstrativo da circulação das ideias do filósofo francês em terras latino americanas.

Utilizando as palavras de Soëtard (2010, p. 26) quando diz que: "Rousseau abriu as portas da humanidade ao coração - a sensibilidade, o sentimento, a paixão -, exigindo que ele estivesse em igualdade com a razão.”, buscamos uma forma para encerrar um texto que não se 
encerra, uma vez que a obra do filósofo Jean-Jacques Rousseau atravessou, e continua atravessando tempos e espaços, suscitando sempre novos questionamentos sobre os eixos: Sociedade e Educação, deslocando assim pesquisadores/as das mais diversas ciências, em especial as Ciências da Educação a sempre se perguntar, sobre o papel da escola, o papel do professor, quem é a criança que aprende e como está aprende, entre outros questionamentos contemporâneos que estão conectados historicamente com a obra de Rousseau, da qual tentamos nos aproximar, discutir e apresentar ao leitor desse texto.

\section{Referências}

ARANHA, M. L. A. História da educação e da pedagogia: geral e Brasil. 3. ed. São Paulo: Moderna, 2006.

ARANHA, M. L. A.; MARTINS, M. H. P. Filosofando: Introdução à Filosofia. 4. ed. São Paulo: Moderna, 2009.

CAMBI, F. História da pedagogia. São Paulo: Fundação Editora da UNESP (FEU), 1999.

FLICK, U. Introdução à pesquisa qualitativa. 3. ed. Porto Alegre: Artmed, 2009.

HIMMELFARB, G. Os caminhos para a modernidade: os iluminismos britânico, francês e americano. São Paulo: Realizações Editora, 2011.

HOHENDORFF, J. V. Como escrever um artigo de revisão sistemática. In: KOLLER, S. H.; COUTO, M. C. P. P.; HOHENDORFF, J. V. (Orgs.). Manual de produção científica. Porto Alegre: Penso, 2014.

LARROYO, F. História geral da pedagogia. São Paulo: Editôra Mestre Jou, 1970.

NOVA ESCOLA. Jean-Jacques Rousseau: O filósofo da liberdade como valor supremo. In: Revista Nova Escola. Edição Especial, Grandes Pensadores. São Paulo: Editora Abril S.A, 2011.

PILETTI, C.; PILETTI, N. Filosofia e história da educação. 8. ed. São Paulo: Editora Ática, 1991.

ROUSSEAU, J-J. O contrato social. Porto Alegre, RS: L\&PM, 2014.

ROUSSEAU, J-J. Emílio; ou, Da educação. 3. ed. Rio de Janeiro: Bertrand Brasil, 1995. 
SOËTARD, M. Jean-Jacques Rousseau. Recife: Fundação Joaquim Nabuco, Editora Massangana, 2010. (Coleção Educadores).

STRECK, D. R. Rousseau \& a educação. 2. ed. Belo Horizonte: Autêntica, 2008.

VASCONCELOS, A. Manual compacto de sociologia. São Paulo: Rideel, 2010.

\section{Como citar este artigo (Formato ABNT):}

GOMES FILHO, Antoniel dos S.; SILVA, Lielton M.; DUARTE, Sandra M. Jean-Jacques Rousseau: Sociedade E Educação. Id on Line Revista Multidisciplinar e de Psicologia, Maio de 2017, vol.11, n.35, p.254-266. ISSN: 1981-1179.

Recebido: 19.02 .2017

Aceito: .08 .04 .2017 